Article

\title{
Some Voices from Italian Youth on Well-Being: How to Cope with Job Insecurity?
}

\author{
Rosy Musumeci ${ }^{1, *(D)}$ and Chiara Ghislieri ${ }^{2}(\mathbb{D}$ \\ 1 Department of Cultures, Politics and Society, University of Turin, 10153 Turin, Italy \\ 2 Department of Psychology, University of Turin, 10124 Turin, Italy; chiara.ghislieri@unito.it \\ * Correspondence: rosy.musumeci@unito.it
}

Received: 25 March 2020; Accepted: 21 April 2020; Published: 23 April 2020

\begin{abstract}
Insecure' jobs and alternating between periods of unemployment and periods of employment under fixed-term contracts are increasingly widespread among the youth in Europe. This phenomenon is an important risk factor for young people's well-being. Despite the growing number of studies, some issues have still not been adequately addressed. Compared to the high number of quantitative studies, the number of qualitative researches is limited: in fact, few studies have tackled this topic from a qualitative standpoint, highlighting the dynamics and the subjective processes which operate in this relationship and considering the different functions that work can have for the individual. Another aspect that has not been adequately dealt with is represented by the coping strategies that young people put in place to deal with job insecurity, and which have consequences on their well-being. The present article on the Italian case is intended to give a contribution in these directions. In particular, it analyses the way in which a group of 40 unemployed or temporarily employed young people, in-depth interviewed, subjectively describe the relationship between job insecurity and well-being, and reflects on coping strategies to face job insecurity and related perceived consequences. In doing this, the authors consider the role of individual factors, as well as of meso and macro ones, given that-for example - the national contexts have a role in influencing the way in which job insecurity is perceived and managed by individuals. The results highlight the complexity of this relationship, in which the intertwining of factors at different levels plays a very important role in determining the coping strategies and the overall well-being of people: individually, like the functions and the subjective meanings of work for the youth, but also in meso and macro terms, such as the familial support and relationships, and the institutional and public resources available.
\end{abstract}

Keywords: job insecurity; unemployment; well-being; Italian youth; qualitative research

\section{Introduction}

'Insecure' jobs and alternating between periods of unemployment and periods of employment under fixed-term contracts are increasingly widespread among the youth in Europe (Baranowska and Gebel 2010). This phenomenon, especially within national and local labour markets that offer few opportunities for young people, is a relevant topic from a scientific point of view and, above all, from a psycho-social perspective in terms of well-being (Giunchi et al. 2016, 2019; De Witte 1999). Temporary employment and other forms of so-called 'flexible' contracts, with few guarantees for employees, are continuing to increase in the World (International Labour Organization 2016), in Europe, and especially in Italy where, in 2016, nearly half of 24-year-olds in employment had fixed-term contracts (46.9\%), compared to ten years earlier, when about one-third of employed youth in the same age group were in that condition (Eurostat 2017). Although workers with a permanent employment contract may also suffer from job insecurity, the rising number of temporary workers and repeated periods of unemployment are important risk factors for people's well-being. 
The link between job insecurity and well-being (both psychological and physical) has been amply documented in the international scientific literature and, as highlighted by a recent review (De Witte et al. 2016), the results of longitudinal quantitative studies have confirmed the hypothesis of causality between this type of insecurity and reduced well-being, increased malaise and health problems. Some studies have also partially confirmed the relationship between job insecurity and satisfaction, work engagement and a number of psychosomatic disorders (ibidem). Studies on gender differences in the job insecurity-well-being relationship suggest that, especially in countries characterised by traditional cultural norms and values about gender roles-for example by the so-called "male breadwinner" model of family-men tend to be more vulnerable than women to job insecurity-related outcomes (Giunchi et al. 2016). The restructuring of gender relations and the growing female participation in the labour market with the related decline of the male breadwinner (Crompton 1999) in contemporary societies suggest that the gender configuration of the job insecurity-well-being relationship could be multifaceted and complex.

Despite the growing number of studies, some issues have still not been adequately addressed from a qualitative perspective, so it would be useful to deepen dynamics and processes and to address further studies, defining more specific hypothesis: for example, the reciprocal relationship (well-being-job insecurity) and the role of functions of work and of coping strategies has rarely been covered in the qualitative literature. In fact, few studies have tackled this topic from a qualitative standpoint, highlighting the subjective processes which operate in this relationship (Blustein et al. 2013).

Given the mainly quantitative nature of these studies, there is no detailed analysis of the perceptions or of the subjective descriptions of the relationship between job insecurity and well-being with reference to predominant emotional experiences and evaluations (e.g., satisfaction with employment and life; Diener et al. 2006).

National contexts, welfare policies, work cultures and the characteristics of both labour supply and demand, as well as personal resources, influence the way in which job insecurity is perceived and managed by individuals (László et al. 2010; Fullin 2004). In Italy, historically characterised by a serious North-South divide, subjective perceptions and experiences of job insecurity vary at territorial level also.

Recent sociological studies on the Italian case focus on how precariousness is experienced, perceived and faced by temporary workers-some considering also those working in the so called 'hybrid areas of work' (Armano and Murgia 2017)—and on its consequences on the youth's working paths, biographies, autonomy and transition to adulthood, also in relation to the historical period marked by the persisting economic crisis (Spanò 2017; Bertolini 2018). Very few studies analyse the explicit consequences of job insecurity and unemployment on young people's well-being and the strategies they use to cope with, react to or resist them.

The general aim of this article is to contribute to filling this gap. Focusing on the Italian case, it analyses the way in which a group of 40 unemployed or temporarily employed young people, interviewed in two cities (Turin in the north of Italy, Catania in the south), subjectively describe the relationship between job insecurity and well-being, the functions of work and reflects on three levels (micro, meso and macro) of coping strategies.

\section{Job Insecurity and Well-Being, between Functions of Work and Coping Strategies}

Well-being is becoming a crucial issue, and some governments have started to think about this as the primary objective of an 'enabling state', as an alternative to the goal of economic growth. For example, in New Zealand, the Prime Minister Jacinda Ardern recently announced that the national budget will focus on citizens' well-being and psychological and mental health; and the Welsh government has established the duty for all public bodies to consider the well-being of future generations (Froud 2019).

Well-being is defined as a multidimensional concept that includes a physical component (health) and a psychological component, which in turn can be divided into cognitive, in terms of satisfaction 
(Diener et al. 1999), and emotional, in terms of prevalent affective experiences (Warr 1990). In the context of work and organisational psychology studies, moreover, well-being is identified with engagement, while malaise is associated with the dimension of emotional exhaustion (Bakker and Demerouti 2017).

Job insecurity is not a simple concept either, but has a multifaceted nature (Van Vuuren 1990). Scholars have distinguished between objective and subjective job insecurity (Näswall and De Witte 2003; Abbiati 2012) and highlighted that insecurity means uncertainty about the future (De Witte 2005), but also refers to doubts concerning the continuation of the job as such (Greenhalgh and Rosenblatt 1984).

Whereas objective job insecurity is linked to fixed-term contracts or other weak employment contracts, perceived job insecurity refers to employees' concerns about the future of their job and fears of losing their job and becoming unemployed (Hartley et al. 1991; Sverke and Hellgren 2002; De Witte 1999). Even though, according to some sources, subjective job insecurity is high among people with fixed-term (or similar) employment contracts, this kind of insecurity may also affect people with permanent contracts, since it refers to a subjective perception influenced by the assessment of the general and specific work environment (Piccoli et al. 2017), perceived employability (De Witte and De Cuyper 2015), personal and social resources (Xanthopoulou et al. 2007). Therefore, the same objective situation may be interpreted in different ways by different individuals (Piccoli et al. 2017).

Job insecurity—so defined—can be conceptualised as a work stressor (Wang et al. 2015). According to the transactional stress theory (Lazarus and Folkman 1984), individuals confronted with a possible stressor undertake a primary appraisal, to decide whether it is a threat to their personal well-being, and a secondary appraisal, to evaluate the resources and coping strategies to be used. When individuals perceive their job as being at risk, they will most likely interpret this as a threat, since employment is important for their personal, social and economic life.

Uncertainty about the future of the job makes it hard to identify and activate useful coping strategies (De Witte 1999), because the source of job insecurity is undefined (it may be related to the employer, but also to the labour market, welfare system and so on): in fact, job insecurity is classified as a rather uncontrollable threat, and people often experience a feeling of powerlessness (Greenhalgh and Rosenblatt 1984).

In line with the definition provided by (Lazarus and Folkman 1984), coping strategies are cognitive, and behavioural efforts to respond to specific external and/or internal stressful demands. Coping strategies can mainly be distinguished as problem-focused (aimed at directly altering the situation) and emotion-focused (aimed at dealing with emotions and cognitions associated with the stressor). In some cases, people use avoidance strategies, such as ignoring or escaping from the situation (Carver et al. 1989): this strategy is used in particular when the source of the strain is perceived as uncontrollable by the person.

According to the literature on stress and coping, the effectiveness of problem-focused and emotion-focused coping strategies depends on whether or not the source of perceived stress is clear (Folkman et al. 1979; Pinquart and Silbereisen 2008); problem-focused coping is more effective with an identified source of stress, while emotion-focused coping seems to be the better choice if the source of stress is unclear (Armstrong-Stassen 2005), as in the case of job insecurity.

However, research on coping as a moderator in the relationship between job insecurity and well-being has produced contradictory results (Richter 2011), and this may also depend on the fact that the studies in question mainly considered general, rather than specific, coping strategies, and that the same coping strategy (e.g., emotion-focused) may have a positive effect on well-being in the short term, but a negative effect in the long term. A recent study (Giunchi et al. 2019) suggests that some problem-focused coping strategies may further worsen the negative relationship between insecurity and well-being (understood as self-related health and life satisfaction).

Moreover, the coping strategies deployed to address the symptoms, for example, health problems, as well as the economic consequences of a precarious working condition, can be located not only at the micro-individual level but also-from a sociological perspective-at the macro and meso social levels. The macro-contexts, where individuals experience their condition of temporary work or 
unemployment, with their peculiar system of public policies and institutions, can provide (or not) to the individuals a set of possible and diversified 'social' strategies to deal with the negative effects of job insecurity, such as, at the meso level, familial and social networks do (Fullin 2004). The Italian case, for example, is characterised by a 'familistic welfare regime' (Esping-Andersen 1999), where the family ties are socially assumed to have-and in practice do have-a very strong role in protecting its members by vary kinds of social and economic risks (included those deriving from job insecurity), and contrariwise, the public protections are weak. To this low level of public protections corresponds low level of trust by people toward public and political institutions.

There are only a few qualitative studies that describe how people faced situations of job insecurity (Bagnara and Bargigli 2009; Heuven et al. 2009; Blustein et al. 2013). Heuven et al. (2009) interviewed 25 employees working in companies in the Netherlands during a restructuring and/or downsizing process, and found that the majority reacted to job insecurity by actively looking for another job, while other respondents were more stressed and reported having developed several psychological problems, which made it impossible for them to actively search for another job. Blustein et al. (2013) found that behaviours aimed at improving employability (e.g., training and education, networking, etc.) limited the negative consequences of unemployment on well-being.

While several quantitative studies have confirmed the link between job insecurity (objective and subjective) and well-being, the dynamics underlying this link are still not completely understood. One possible process is based on the function of employment for people. Employment has manifest and latent functions (Merton 1949; Jahoda 1982; Van Hoye and Lootens 2013): the manifest function is related to financial benefits; the latent function is related to the fact that having a job imposes a time structure on personal life, and this may help people to have a comfort zone. Having a job also means individuals can be active in life and attain individual and common goals.

Following Jahoda's latent deprivation model, job insecurity has a negative impact on well-being, not only because of concerns about not having an adequate income at present (and in the future), but also because of the loss of a collective purpose and of an adequate time structure in daily life (Paul and Moser 2009).

The social identity theory (Tajfel and Turner 1979) can also be helpful for understanding the 'job insecurity-well-being' relationship. Identity issues are particularly relevant in the current fragmented and discontinuous world (Albert et al. 2000; Piccoli et al. 2017): the organisational context has been addressed as a field of application of the social identity perspective (Van Knippenberg et al. 2002). In this frame, the workplace is not only the place in which people fulfil their financial needs and give a structure to time, but it also enables social identification with a specific organisation and, sometimes, with meaningful work (Steger and Dik 2009), allowing people to express (and enhance) their skills and competence. When people have a job with an identity value, perceived well-being is not undermined, even in the condition of precarity.

\section{Job Insecurity in the Italian Context: The Youth Case}

Previous Italian quantitative studies (Ciairano et al. 2010) have highlighted the link between precarious employment situations and satisfaction, for example, indicating the fundamental role played by meaningful work in fostering satisfying experiences. But what is the youth situation in Italy in terms of job insecurity and their employment condition in the labour market?

It is well known that, in Italy, the youth employment situation has always been worse than that of adults in comparison to other European countries (lower employment rates and higher unemployment rates) (Reyneri 2017), and the situation worsened even further during the 2009 economic crisis: in Italy, in 2016, nearly half of employed youth aged 24 had a fixed-term contract (46.9\%), compared to ten years earlier when about one-third of employed youth in the same age group were in that condition in Italy (Eurostat 2017). 
The economic and financial crisis broke out in 2009 and was not the only cause of this situation. In recent decades, several labour market reforms have been introduced in many European countries, with the aim of increasing flexibility and making it easier for young people to find work.

Italy's first steps in the direction of deregulating the labour market date back to the early 1980s, first with the introduction of training and work contracts ('contratti di formazione lavoro') (1983-1984), then by making it more convenient for enterprises to use fixed-term contracts (L. 451/1994; L. 608/1996). This type of deregulation, in the 1990s, gave way to open liberalisation; the decisive turning point came in particular in 1997, when the Treu Law (n. 196) came into force. Greater elements of flexibility were introduced in the Italian labour market and new types of contracts, such as temporary agency work ('lavoro interinale'). The liberalisation process reached its climax with the approval of Law 30/2003, which seems to have marked the transition from the flexibility model as a 'controlled derogation' to that of flexibility as a 'general principle', on the Anglo-Saxon model of scarce social protections for workers who experience job insecurity. More recently, the Italian Government introduced the Law 183/2014 (the so-called 'Jobs Act').

These reforms have actually had the effect of making the job search more difficult for many young people; with the spread of temporary employment contracts, the working paths of young people in Italy have become increasingly fragmented and discontinuous.

This not only results in a huge waste of young human resources, who have, on average, higher levels of education than previous generations (Rosina 2018), it also has a serious impact on young people's lives. Today's young people often have different and discontinuous jobs in their working life and often earn inadequate incomes (Fana 2019), even though they do not work fewer hours than their parents' generations. Job discontinuity can create a feeling of insecurity in many young people, frustration and pessimism about their future, especially if this condition occurs repeatedly over the years and, as shown by previous studies regarding European youth (Aassve et al. 2002; Blossfeld et al. 2005), it can indeed lead many of them to postpone or even abandon binding long-term decisions such as marriage, living together and having children. The increasing discontinuity of the work and labour market uncertainties generate a discontinuity of income, which, in turn, can make it difficult for young people to achieve full economic, housing and even psychological autonomy (for the Italian case see Bertolini 2018; for a cross-national comparison see Bertolini et al. 2018). These effects are particularly evident in a country like Italy where, from a cross-country comparative perspective, perceived job insecurity among temporary workers is even higher, as reported, for example, by studies on young-adults aged 25-44 (Naticchioni and Muzi 2007).

When talking about the implications of job insecurity on young people's lives in the Italian context, it is important to note that both the experiences and the subjective perceptions of job insecurity can vary at territorial level. First of all because North and South are characterised by different models of flexibilitation of the labour market: the market flexicurity in the first case, the flex-insecurity in the second one (Avola 2009; Berton et al. 2009). Moreover, there are different structural and institutional dimensions of the North-South divide, which influence the generational inequalities and employment discrimination by age, such as, for example, the different level of qualification of youth labour demand and supply (Reyneri and Pintaldi 2013), the profile of the welfare regime and the different mix between market, state and family (Sgritta 2014; Ferrera 2012).

In Italy, as in other European countries, specific policy measures, such as the Youth Guarantee program, have been implemented, in order to improve job prospects and the employment situation for young people. On the basis of the alarming growth of youth's unemployment and NEET rates because the economic crisis, in 2013, the European Union has developed a specific and innovative program called the Youth Employment Initiative, aimed at encouraging the reversal of the negative trends recorded. In particular, with the Recommendation of the Council of the European Union of 22 April 2013 on establishing a 'Youth Guarantee', Member States have been invited to ensure that all young people under the age of 25 years receive a good-quality offer of employment, continued 
education, apprenticeship or traineeship within a period of four months of becoming unemployed or leaving the formal education system.

In Italy, significant territorial differences between the North and the South have been registered in the implementation of this policy program; the implementation of employment policies for young people appears weaker and more difficult in the Southern regions. For example, for the Sicilian case, Avola et al. (2017) noted that in the public employment centres the operators called to carry out the complicated role of facilitator in the matching of job supply-demand were low educated and lacking a minimum supply of operational tools (computers and even paper and chancellery).

Starting from a multidisciplinary scientific literature, mainly related to psychology and sociology, the aim of this study is to qualitatively deepen, through interviews with the precarious Italian youth, the nature of the relationship between job insecurity, well-being and coping strategies, considering the role of the meaning that work can take (financial, time structuring, identity) in modulating the experiences of well-being and in defining coping strategies. Furthermore, with respect to the latter, the study wants to explore the effects of coping strategies adopted at a micro level (considering problem-focused, emotion focused and avoidance), at a meso level (social proximal context), and at a macro level (institutions and policies), on well-being and precariousness, grounded in narratives from Italian youth.

\section{Data and Method}

The empirical material analysed in the present article is composed of 40 narrative semi-structured interviews conducted with young people based in Italy between December 2015 and September 2016, as part of a European project (Horizon 2020), which involved conducting interviews with 386 young people in nine countries with the same interview outline-covering three thematic areas: autonomy, well-being/health, socio-economic consequences-and following common sampling criteria. The main aim of this research project was to explore how young people perceive their situation as unemployed or temporary/precarious workers, and how they cope with this in different institutional, economic and cultural contexts, with particular regard to three life domains: autonomy, well-being and socio-economic status.

The analytical method we use in this article is consistent with the qualitative research as a scientific method of observation, focusing on the meaning-making processes and dynamics, and aimed to answer questions related to why or how a certain phenomenon occur, rather than how often it occurs (differently by quantitative method gathering and analysing numerical data). Given this analytical goal, the ideal was to have a number not so high of cases/interviews to allow an in-depth analysis (Babbie 2014; Krauss 2005; Denzin and Lincoln 2005; Berg and Lune 2012).

The 40 interviewees were aged 18-30. Some of them (18) were unemployed, others (17) were employed with a fixed-term contract or without a regular employment contract (5). The original sample was composed of 50 young people, and it included 5 NEET and 6 permanent workers. For our analytical purposes, we did not consider these 10 interviews. They lived in two Italian cities: Turin in the north (25) and Catania in the south (15).

The main characteristics of the qualitative sample based in Italy are summarised in the following table (Table 1):

Table 1. Participants.

\begin{tabular}{|c|c|c|c|c|c|c|c|c|c|c|c|}
\hline & \multirow{2}{*}{\multicolumn{2}{|c|}{ Gender }} & \multirow{2}{*}{\multicolumn{2}{|c|}{ Age }} & \multirow{2}{*}{\multicolumn{3}{|c|}{$\begin{array}{l}\text { Educational Level } \\
\text { (ISCED) }\end{array}$}} & \multirow{2}{*}{\multicolumn{2}{|c|}{$\begin{array}{c}\text { Occupational } \\
\text { Status }\end{array}$}} & \multirow{2}{*}{\multicolumn{2}{|c|}{$\begin{array}{l}\text { Geographical } \\
\text { Context }\end{array}$}} \\
\hline & & & & & & & & & & & \\
\hline & $\mathbf{M}$ & $\mathbf{F}$ & $18-24$ & $25-30$ & Prim. & Sec. & Tert. & $\begin{array}{c}\text { Temp. } \\
\text { Contract }\end{array}$ & $\begin{array}{l}\text { Unempl. or Not } \\
\text { Contractual Job }\end{array}$ & Turin & Catania \\
\hline $\begin{array}{c}\text { N. of } \\
\text { interviewees }\end{array}$ & 18 & 22 & 20 & 20 & 9 & 21 & 10 & 17 & 23 & 25 & 15 \\
\hline
\end{tabular}


The interview outline for the qualitative interviews was divided into the following sections: warm-up questions, educational and working paths, work (perceptions, feelings and satisfaction), informal and institutional support, living conditions, economic status and autonomy, plans and future prospects.

Well-being and coping strategies were treated as cross-sectional topics to be investigated throughout the interview. For the purposes of our analysis, we focused on the answers to the questions about the relationship between job insecurity/unemployment and well-being.

The sample was built through formal and informal recruitment channels. Overall, 23 interviews were obtained through institutional channels, and 17 through informal ones. Regarding the first kind of recruitment channels, young people were signalled by relevant public offices, such as employment offices, associations and training institutions, according to the sampling criteria provided by the research team. In the case of the informal channels (i.e., personal networks) the 'snowball' sampling method (Goodman 1961) was used. The use of these two types of channels is the result of a sampling strategy aimed to include, in all the national samples involved in the H2020 project, respondents contacted through different recruitment channels in order to minimise the over-representation of some channels on others.

The average duration of each interview was $1-1 \frac{1}{2}$ hours. No financial incentives were used. The interviewers involved were 3 postdoctoral researchers, who also transcribed the interviews verbatim.

Particular attention was paid to ethical aspects in contacting people and performing interviews. The interviewers conducted the interviews in accordance with ad hoc ethical guidelines, and each interviewee signed an informed consent form. Aliases (invented names) were used in place of real names, to protect the interviewees' privacy and identity.

To analyse the empirical material, we used two main analytical tools, driven by the literature: a codebook for coding and extracting parts of interviews concerning specific themes and subthemes, and a synopsis. Both tools were shared with all the other national teams.

The codebook was based both on the literature and on a first reading of the interviews. The synopsis was a summary of each interview according to a template generated on the basis of the codebook with dimensions shared among the researchers; it also contained the interviewers' notes (on the interview setting, interviewees' attitudes and non-verbal communication), and quotations considering interviewees' experiences, coping strategies, feelings and points of views.

In order to reach a homogeneous analytical approach and make sure that the interviews were coded and summarised in a similar way. In a preliminarily step, the researchers involved in the team coded and analysed the same interviews and then discussed their findings.

\section{Main Findings}

\subsection{Job Insecurity, Functions of Work and Well-Being}

Various interconnections between job insecurity and well-being emerged from the interviews, different functions of work emerge among the interviewees, and on the basis of these differences the relationship between job insecurity and well-being changes (Albert et al. 2000; Paul and Moser 2009; Piccoli et al. 2017; Van Knippenberg et al. 2002; Van Hoye and Lootens 2013).

In line with the international literature (Baranowska and Gebel 2010), unemployment leaves a mark on the interviewees' lives, with traces persisting even after the period of unemployment has ended: the interviews reveal a sense of malaise and depressive moods, related to a feeling of disheartenment because of poor labour market prospects. 
For Luigi (29, M, ME, $\mathrm{NCJ}^{1}$ ), for example, the most difficult moment was when he was laid off and left without an income: a period of six months which had an extremely negative impact on his well-being.

In some interviews, people attribute a fundamental instrumental function to work in supporting the thinking about their identity in the present and in the future. The main issue is related to a sense of hopelessness. Mara (Mara, 30, F, ME, U) said that she feels depressed because of her jobless status, which ties up with a sense of failure, disenchantment, malaise and an increasing state of neglect and surrender. A feeling of deep sadness and frustration caused by failing to find a new job emerges from her interview, but also from the narratives of Concita (23, F, ME, U): this translates into looking to the future with despair and pessimism, or, in the words of Mara, feeling that 'you do not have a future'.

In line with Jahoda's idea that work gives a time structure to personal life, and that this can create a comfort zone, in some interviews, the feeling of disorientation concerns the present time. Tommaso $(22, \mathrm{M}, \mathrm{ME}, \mathrm{U})$ talked about how, in the second week of unemployment, the lack of work meant he had too much free time, which he was unable to appreciate: the days were all empty and every one was exactly the same.

In the case of Emma, a young interviewee, well-being is related to the economic autonomy gained through work, even if in a precarious situation: however, this well-being is closely linked to the immediate present (Emma, 20, F, ME, TE).

In other interviews, work is mainly considered a fundamental instrument of identity construction, as long as it is compatible with family and private life.

For Antonio, after an experience of school largely characterised by episodes of malaise, work, even if insecure, represents a source of satisfaction, also because he lives with a focus on the present, without thinking too much about the future. The reason for this work-related well-being derives from the fact that he perceives that he is capable and that his abilities are acknowledged.

Yes, this one I like. Because anyway it's not a job where you sweat and so on. But, apart from that, I enjoy it because it seems, apart from the fact that I like it, it seems I have the right skills to do certain things, I feel good there. (Antonio, 19, M, LE, TE)

Work, in fact, can be a source of well-being, even when it is not 'secure': having a meaningful work (Steger and Dik 2009), consistent with one's personal interests and values, can lead to a feeling of satisfaction, as in Franco's words:

... working, if you're doing a job you like, even makes you feel good about yourself, you fill your time usefully. And this is what I was looking for, basically; I was looking for a job which (... ) gave me something, let's say, yes, something like, it also helped me to grow. (Franco, 30, M, HE, NCJ)

Chiara, too, describes her cash-in-hand job as an element of well-being, because it corresponds to her own interest in working in the fashion industry, and follows on from a difficult period in her life plagued by personal problems and a negative situation at work, where her boss was particularly demanding:

I went through quite a difficult time, I was really frustrated. I mean, now I almost feel like I'm coming out of a tunnel, so ... [ . . . ] I mean, I had my fashion project, I had my ... fashion line ... my own small jobs, it's not that I was completely ... without a thing. (Chiara, F, 28, $\mathrm{ME}, \mathrm{NCJ})$

1 The labels in brackets refer to interviewees' age, gender, educational level, employment status. Female = F, Male = M; low educated $=\mathrm{LE}$, medium educated $=\mathrm{ME}$, high educated $=\mathrm{HE}$; Temporary employee $=\mathrm{TE}, \mathrm{Unemployment}=\mathrm{U}$, Non contractual job = NCJ. The interview excerpts are translated also including speech defects. 
Ionela also reports predominantly positive experiences. Originally from Latvia, Ionela is 25 years old and recently started a new job, with a fixed-term contract, with an event management company. She is dynamic, motivated and draws satisfaction from her current job, which seems to her to be an excellent opportunity. She appreciates all aspects of her job, above all the relational side, the fact that she moves in an international environment, and also the challenge to grow professionally:

I like everything. I like the people, because we are very international, from all parts of the world ... there are some really very nice people, and it's also interesting because the new level in my career, with goals, you see the goals to follow, it's not just a job to do so you can say 'OK, I get home at the end of the month I've got the money', no, you work with an idea, that's why I really like it. This is the motivation. (Ionela, F, 25, HE, TE)

In the narratives of these Italian youth, especially for people with medium-high educational qualifications, even in conditions of contractual insecurity, a strong focus on work as an identity-building tool seems not only to mitigate the negative effects of insecurity on well-being, but also nurtures work engagement and performing work-related tasks to build a positive state of mind (Bakker and Demerouti 2017).

This effect disappears when youth experience a destructive leadership (Molino et al. 2019): through an excessive increase in workload and a despotic style, destructive leaders generate emotional exhaustion and produce the intention to quit the job. In this case, the work that has the power to undermine well-being: Concita, for example, describes her experiences of work for a photographer, as both very hard and frustrating:

Working at a call centre was psychologically exhausting ... so much so that when I got home I didn't want to talk to anyone. [ ... ] The worst experience was with the photographer ... (laughs) The owner of the shop has traumatised me. (Concita, F, 23, ME, U)

Katia (28 years old, currently unemployed) experienced malaise and chose to leave the job, even though it offered her the opportunity for professional growth: the environment was characterised by a despotic leadership and a negative atmosphere, high demands and little collaboration or support, so she decided to leave her job and to look for a better one (without any guarantee of being able to find it where she lived, Catania, a context characterised by a very weak labour market), that would allow her to feel well at work.

I signed a contract for 3 months, but then 10 days ago, I decided that ... I had to choose between work and feeling all right, and I chose to feel all right. (Katia, F, 28, HE, U)

\subsection{Coping Strategies}

\subsubsection{Micro-Level Coping Strategies}

Job search is a specific kind of problem-focused coping strategy related to job insecurity, covering a wide spectrum of micro-strategies. Looking for a job by sending out CVs is, literally, an 'active' coping strategy but in some cases, this can generate malaise, in accordance to others quantitative studies (Giunchi et al. 2019):

I took my CV everywhere (... ) I'd turn round to leave, and out of the corner of my eye, I'd see that my CV had been shredded. (Aurelio, 23, M, ME, TE)

In fact, in some cases, a wide range of emotions are associated with the process of searching for a job: Renata's current self-representation, for example, is characterised by a sort of ambivalence (optimistic but also worried), linked to her having enthusiasm but, at the same time, being afraid of not knowing what to do, considering that all her peers are in a very similar situation. The result is a rollercoaster of emotions: 
I mean I feel inside myself like I have two personalities: on the one hand, I tell myself: 'Oh my God there I'll do it! I'm scared! Not ... eee ... ' But on the other I say: 'But at this point I have to do it' ( ... ) (Renata, 22, F, ME, U)

It seems that when people do not have a strong career identity and the focus is mainly on economic and structuration of life functions of work, people strive to search for a job, whatever it is, without any strategy of identification and contact with possible employers. This strategy is rarely successful, increasing the experiences of malaise associated with the employment condition.

Renata, like other interviewees, highlights the comparison with her peers and, in doing so, relativises her condition of job insecurity.

I'm in the same boat as my peers, and I think it is a time of life that all people have been through (Renata, 22, F, ME, U)

Others seek to 'escape' the psychological discontent associated with the impossibility of getting a sense of fulfilment from their job in their own country by planning to emigrate. This is, for example, the case of Gaia, who is planning to follow her American boyfriend to the USA. However, while, on the one hand, she describes this strategy as necessary for her personal fulfilment and in order to live happily, on the other, she does not hide the malaise and the emotional costs which she would experience in a 'forced' emigration:

I wouldn't not like to leave Sicily because it' is my home, my place, but/what can I do/? (Bitterly) It's spirit of survival! [ ... ]/However you cannot bring a person to the point of marrying another person just because here, in Sicily, there is no life and a future/(said quietly). (Gaia, 24, F, ME, U)

Emotion-focused coping strategies (Lazarus and Folkman 1984) are used exclusively or as an accompaniment to problem-focused strategies, to limit the negative emotional consequences of insecurity, but also of frustration, due to the absence of results related to job search with weak strategies. Some people seek to offset a low income with fun opportunities as a way of coping emotionally with the working situation and attaining some kind of 'short-term happiness'. For Erika (29, F, LE, U), this can simply mean being able to treat herself to a pizza or a dish of pasta in a restaurant once in a while.

In order to reach a state of well-being, some people search for a compensation outside the work domain, pursuing hobbies or doing voluntary work: in this sense, art, music and sport are considered effective coping tools by the interviewees. Only one interviewee (Margherita, 24, F, ME, U) mentioned turning to a psychologist for support.

Also avoidance and denial are (no)-coping strategies cited in interviews: in many cases, to overcome the feeling of being crushed, and subsequently of not being able to look beyond the present, the interviewees reported using a particular strategy to 'avoid thinking about the present', in order to cope with the anxiety and concern associated with the insecurity of their job.

That is the case of Aurelio (23, M, ME, TE) who, as a defence against anxiety, avoids thinking about the present or what the situation will be in the future. In the previous cited case of Luigi, the loss of structure of life in the unemployment period was such a traumatic experience that he is unable to reconstruct it accurately, as if a process of denial has come into play:

I mean, I think this ... this condition has affected my mind so much that I'm tending to forget! (Luigi, 29, M, ME, NCJ)

If Luigi forgets the past, Emma cancels the thought of the future. To cope with the worry about the future, the only solution is a cognitive restructuring of the life perspective, trying not to think about the future and to remain grounded in the present: 
I mean, I try to keep calm and not think about it, because if you always live with a knot in your stomach, about everything. Sometimes it's better to think about it but not too much, because otherwise you get really paranoid, worry about everything and you never get to live. (Emma, 20, F, ME, TE)

In other cases, the thought of sharing the same employment situation with their contemporaries, and of being exposed to the same risks (including to health) serves as a micro coping strategy to emotionally and mentally control dissatisfaction, and to prevent insecurity and the lack of work from giving rise to severe malaise. For example, Ester (26, F, ME, NCJ) thinks that she shares this discomfort with many of her peers, and feels that she does not want to end up like many young people who develop full-blown psychological conditions. She has therefore tried to rid herself of her discomfort, so as not to fall victim to panic attacks and the need for medication.

When work has a strong identity value, on the other hand, rather than denying precariousness, young people accentuate the advantages related precisely to the opportunity to express self-components, and to live in a rich relational context: is the case of Franco (30, M, HE, TE), who seeks to enhance the positive aspects of his job despite its precariousness.

\subsubsection{Meso-Level Coping Strategies}

In line with the studies describing the Italian context as characterised by a "familistic welfare regime" (Esping-Andersen 1999), where the family ties are socially assumed to have-and in practice do have-a very strong role in protecting its members by vary kinds of social and economic risks, family (of origin, and in certain cases also uncles and aunts, grandparents or peers such as cousins) appears to be the most significant source of emotional and psychological support for our young interviewees.

For example, Mara is looking for a job and says she is depressed:

Not finding anything has made me feel very low//of course//and so ... ... I've also been through periods of depression ... [ ... ] It's a weight, yes sure, especially now that I'm thirty years old//Of course//yes sure, I'd say that at the moment I'm suffering from depression ... . (Mara, 30, F, ME, U)

Her parents are doing their best to support her psychologically and emotionally at a time when she feels bad about not having a job. Her family's emotional support is so important to her that it is preventing her from considering the idea of emigrating to find work:

To be honest, I have no desire to go abroad, because my family is here $/ / \mathrm{mhm} / /$. . . so many people go, maybe I don't have the guts ... let's put it that way [ ... ] why should I have to go? (Mara, 29, F, ME, U)

Likewise, Renata (22, F, ME, U), who describes herself as an energetic and optimistic girl, turns to her family of origin for considerable support, and it is there that she finds the motivation and encouragement to carry on without becoming depressed by the challenges of the labour market. She is still well-integrated within the environment in which she lives, thanks to strong and significant protection given by her family of origin, which appears to be financially and emotionally stable.

While many of the interviewees stated that they have turned to, and greatly appreciate, the emotional support of their families of origin, a fair number basically consider this inadequate to contain the malaise associated with their employment situation, albeit acknowledging that this support impacts positively on their well-being and mental stability.

For example, Camilla (23, F, ME, NCJ), who, for the moment, is satisfied with her present living conditions (she lives in the countryside with both parents and one sister in a detached house built by her parents), has a strong desire to leave her parents' home and move in with her boyfriend. She would have liked to have left her parents' home before, when she was about 20, but was unable to go and live with her boyfriend, because of her employment situation. 
In some cases, despite appreciating the support provided by the family, the interviewees consider this to be ineffective for coping with the real cause of their malaise, namely being out of work; for example, Franco said:

My mum ... I mean, she tries to help me, to support me ... but for how I am, these are words that don't work with me. You feel like a looser, useless ... It's bad. [ .. . ] what would make the situation less complicated, is a job. (Franco, 29, M, HE, NCJ)

But not always the family atmosphere is so supportive from an emotional point of view, therefore, in these cases, being 'forced' to live with the family of origin because they are unable to be independent, in terms of having a home of their own, given the unstable employment situation, emerges as a real source of tension and malaise among the young interviewees. This, for example, is the case for Erika, who is stressed because she has to do most of the daily chores (this is also why she would very much like to leave the parental home):

I do everything. My mother can't do it. She's the kind of person who gets confused and [... ] She's lazy. [ ... ] I understand that she has all her physical ailments, BUT SHE MUST MOVE BECAUSE SHE'S LAZY! [ . . . ] And I try to be patient/(venting her feelings). (Erika, $29, \mathrm{~F}, \mathrm{LE}, \mathrm{U})$

Other interviewees experiencing a situation of tension in the family of origin who are not supportive, utilise different channels and relationships to cope with the malaise and the sense of dissatisfaction with their employment circumstances. For example, Tamara, who lives in Catania in Southern Italy, a territorial context where the proportion of practicing believers is higher than the North (Istat 2016), says she derives some comfort and peace of mind from going to church with her family, from whom she also receives some basic financial and practical support:

We started to attend church during a difficult time in our lives; we try to relax a bit in church. (Tamara, 23, F, ME, U)

According to Istat (2016) the share of practising believers is 33.5\% in Southern Italy, $27.7 \%$ in the North-West, $26.8 \%$, in the North-East and $25.0 \%$ in the Centre. Sicily, where Catania is located, is the Italian region with the highest religious practice $(37.3 \%)$. In our sample of interviewees, the half of youth in Turin declared that they were atheist, only three declared that they practiced some religion (catholic, protestant or Islam), while the other 10 did not answer the question on religious affiliation; in Catania, the share of young interviewees explicitly declaring that they were atheist was much lower (only two out of 15), while 12 out of 15 declared themselves Catholic.

In certain cases, even, or above all, friends (or boy/girlfriends) are a source of emotional and psychological support. For example, one of Antonio's important points of reference is a friend who is two years older than him, and the only one who is already in employment, because the others are all still in school. Although he cannot discuss work with the latter, he still receives their support, which he considers crucial at a psychological level in his transition from student life to that of a worker, which requires greater commitment.

\subsubsection{Macro-Level Coping Strategies}

As mentioned in Section 2, the system of public policies and institutions in a specific national context can provide the individuals with a set of possible strategies to deal with their job insecurity experiences.

Among those who seek and/or receive support from public institutions in order to deal with health and well-being issues linked to their employment situation, Gaia (24, F, ME, U) reported a very positive experience: she found work through the Youth Guarantee programme (and a 'role', she said).

Erika's point of view is similar. She found her last job thanks to the Youth Guarantee programme. This is the job she has held for the longest time in her fragmented ten-year working life, and also the 
best paid (500 euros a month). She was very enthusiastic about this job and she considers it the best working experience in her life. She would have liked to continue that experience; unfortunately-she said - the factory was not able to employ her after the six-month period of paid training and she was dismissed.

Max (27, M, ME, PE), too, is satisfied that he made use of the institutional channel to cope with his situation. He is very satisfied with the courses, because he thinks that they had a significant impact on his life and well-being. The factory work started to become a passion and he tried to change jobs, leaving the company and going into a confectionery shop.

While there are no shortages of cases like the ones cited above-of appreciation of the possibilities afforded by macro strategies to cope with their malaise-many interviewees declared that they have no faith in the ability of politicians and institutions to improve their situation. At times, lines of argument such as these seem to be an 'excuse' to avoid being proactive and developing so-called macro coping strategies. Several of these young people said they are not entirely convinced that the institutions are interested in doing anything practical to help youth. At times, the interviewees drew on the direct experience of their peers for want of any of their own, on other occasions, their negative evaluation of macro coping strategies was based on their own direct experience of such strategies and their negative outcomes. Many interviewees, especially those based in Catania, reported that, after completing the Youth Guarantee online application form, they were never contacted by the Employment Office for an interview. Others reported that there was too much bureaucracy involved in order to start and complete the Youth Guarantee internship. Other interviewees who attended courses organised by regional government public training institutes found them to be very disorganised, and this left a bad impression, which made them decide to quit the course after only a few days. As for the Employment Offices, some interviewees like Anna (27, F, HE, TE) tried to use them, but found they did not respond to their specific needs and, moreover, they did not provide enough and adequate information.

\section{Discussion and Conclusions}

This study analysed the experiences and the feelings of a group of young interviewees based in Italy, with regard to the link between job insecurity, well-being and micro, meso and macro coping strategies, taking into account the different functions and meanings of work for the people involved.

The results highlight some critical and crucial dynamics. The relationship between job insecurity (especially the unemployment period) and the worsening of well-being is clearly grounded in Italian youth's narratives. The experience of unemployment is associated with strong economic concerns but, above all, it is accompanied by depressive feelings - in line with international quantitative studies (De Witte et al. 2016)—and linked to the sense of emptiness, as the days gradually become more and more devoid of any time structure and of any transition between different places, different roles and different relationships.

The link between job insecurity and malaise is present, above all, in the stories of youth with low or medium educational qualifications, and with an idea of work as economic support and as a form of structure of life and time. The feeling of spare time gradually turning into a prison was described well by the young interviewee who talked about the importance of the latent function of work to define a structure in personal life (Jahoda 1982; Van Hoye and Lootens 2013).

On the other hand, when work, although not contractual or precarious, has a strong identity value, young people experience fewer negative consequences, in the short and medium term, on perceived well-being. In relation to this, it is important to observe how doing 'significant work' represents a protective factor (Ciairano et al. 2010) against the malaise that can sometimes be associated with work (caused by job insecurity but also by excessive workloads and cognitive demands), and not just with being out of work.

However, this positive element also has a 'dark side'. We observed this phenomenon in the narratives of the young interviewees: when work is considered significant and relevant, young people are more inclined to accept contract terms that provide very little protection and are not consistent 
with the type of job, or even to work illegally. They accept these conditions because they perceive the overall situation as critical, and they compare themselves with their peers in similar situations. The picture that emerges from the interviews-in terms of the 'treatment' of some of the young people interviewed in the Italian labour market-is of situations characterised by exploitation, lack of respect and an instrumental use of the need to work and the desire to do a significant job. This dynamic is risky and future studies should evaluate its impact in quantitative terms.

Despite coping strategies, the interviews highlight a wide diffusion of processes of denial or cognitive avoidance of problems (Carver et al. 1989). The lack of a 'comfort zone' for the present also casts a dark shadow on the future, not only in periods of unemployment but also in many precarious employment situations - this leads to people 'shortening their view' to prevent themselves from seeing possible future problems and being overwhelmed by anxiety. This coping strategy, consisting in avoidance and negation, seems to have 'relief' effects in the present; the future consequences of this attitude and of the set of behaviours associated with it (disinvestment, lack of activation, lack of planning) need to be carefully assessed.

In situations of job insecurity, for people with low-medium educational qualifications and an idea of work that mainly focuses on economic needs and its nature as a life-time regulation tool, their strategies focused on their prevailing problems were not very strategic (sending out CVs randomly) and generated high levels of malaise, because refusals and failures were frequent, which accumulated their sense of frustration and consolidated their feeling of hopelessness (Giunchi et al. 2019). The interviews for this study introduce some different possibilities to be considered with greater attention in future quantitative studies: the level of education, the quality of problem-focused strategies and, as highlighted, the work functions prevalent for the person and the meaning attributed to it.

On the other hand, youth with medium or high levels of education and a high identity value of their job suffer less from negative consequences related to precariousness in the short term-in relation to this, they make less use of active but disordered coping strategies. In general, the threatening meaning of precariousness is weakened through a selective cognitive process that enables the individual to pay attention, above all, to the positive aspects of the job, to the possibility of self-expression and to recognising themselves as competent. If this strategy has immediate positive effects, it produces, by contrast, a phenomenon of acceptance of many disadvantageous employment conditions, with economic consequences in the medium-long term.

There is, however, an exception. When the young interviewees experienced problematic relationships, especially with the supervisor/the boss, the meaning of the job stopped being a protective factor. In the presence of the dark side of leadership, the process of identification and significant work can 'get lost' (Ghislieri et al. 2019).

Confirming the previous literature highlighting the crucial role of family, in the Italian context, as a protective factor for individuals in many fields, owing to the overall weakness of the national welfare system (Saraceno and Keck 2010) and as an important resource for coping with the risks and negative consequences of job insecurity (Fullin 2004), the family of origin emerged from our analysis as the most significant source of emotional and psychological (as well as financial) support for the young people we interviewed. The criticalities of this aspect are already beginning to show, but this could become a real problem in the absence of a strong welfare system in the future, and scholars have already started to reflect on whether and how the young people of today will be able to fulfil that same function of informal support for their own children, since they will not enjoy the same income guarantees at the end of their working career, having paid fewer social security contributions and with greater discontinuity (Reyneri 2017).

Although the possibility of finding satisfactory employment in terms of financial sustenance and identity integration is high, for many young people we interviewed, doing a job that fails to mirror their own personal identity and that is not consistent with their interests and skills is a real problem: this situation does not reduce the centrality they attributed to work in the identity construction process, 
but the idea of finding the 'right job for you' continues to guide training and employment choices, especially for young people with medium-high educational levels. The contemporary occupational situation is marked by the drama of youth employment. On the one hand, young people are required to have experience, to demonstrate accountability and professionalism and an almost sacrificial dedication to work, while on the other hand, the labour market remains rigid, recruitment and selection policies are closed and generate frustration among job seekers and, in the experiences of the young people interviewed in Italy, entrepreneurship appears to be 'youth-unfriendly', when not a decidedly 'exploitative' environment.

This also clashes with the fact that while, in some cases, the interviewees declared themselves willing to accept a job 'whatever it is', in most cases they consider work as a sphere in which to express their identity, an opportunity to grow, establish a connection with significant others and find a work-life balance (Savickas et al. 2009). This fact confirms that, despite a further weakening of attachment to the labour market, the latter element continues to be considered significant by young people. And when they are unable to find a job that is satisfactory in terms of self-identity, they adopt a coping strategy which allows them to maintain a certain degree of detachment from the source of their malaise.

This element, together with the interviewees' perception that they receive inadequate support from the institutions, requires a great deal of attention.

In this respect, it is worth mentioning that, while there is no shortage of cases in which interviewees appreciated the possibilities afforded by macro strategies to cope with their malaise and focused on improving their employment situations and employability, through policies and institutional channels, many of them said they have no faith in the ability of politicians and institutions to improve their situation, and feel discouraged and helpless in the face of a system perceived as distorted. Several of the interviewees said they are not entirely convinced that the institutions have any interest in doing anything practical to help young people. Another open question regards the absence of free psychological support services for precarious or unemployed people.

The availability of psychological support services represents an important well-being policy, but is still not widespread, although some universities, schools and vocational training institutions are currently investing in psychological support services; services like these must be clearly visible and accessible, including through the network of job services.

In addition to this, the present study highlights the need of individualised policies and guidance interventions based on each person's life story (Savickas et al. 2009), aimed at making young people aware of their own human capital (Chiesa et al. 2018): these interventions could act on the psychological factors underlying an effective and strategic employment search.

The interventions aimed at enhancing employability are linked to issues of strengthening entrepreneurial intention, or paths to enhancing the achievement of objectives, and are attentive to gender differences and socio-economic origin (Molino et al. 2018; Ojala et al. 2019). Although these are useful, they should be balanced with important socio-political actions to effect employment and-with a massive education and training of the Italian leadership-aimed at affecting entrepreneurial and managerial cultures. We refer to education and training projects about workers' well-being and sustainability, not as mere fulfilments, but as duties and, at the same time, as offering substantial advantages for individuals and for the community.

Author Contributions: Conceptualisation C.G. and R.M.; introduction C.G. and R.M.; theoretical framework, C.G. about the main framework and about the psychological aspects and R.M. about the sociological aspects; methodology, R.M.; investigation and data analysis, R.M. and C.G.; writing-review and editing, R.M. and C.G.; supervision, C.G. All authors have read and agreed to the published version of the manuscript.

Funding: This research was funded by European Union (H2020), EXCEPT project ('Social Exclusion of Youth in Europe: Cumulative Disadvantage, Coping Strategies, Effective Policies and Transfer'), grant agreement No 649496.

Conflicts of Interest: The authors declare no conflict of interest. 


\section{References}

Aassve, Arnstein, Francesco C. Billari, Stefano Mazzucco, and Fausta Ongaro. 2002. Leaving home: A comparative analysis of ECHP data. Journal of European Social Policy 12: 259-75. [CrossRef]

Abbiati, Giovanni. 2012. Instabilità, precarietà, insicurezza. Cosa si intende quando si parla di «insicurezza» del lavoro? [Instability, precariousness, insecurity. What do we mean when we talk about job «insecurity»]? Stato e Mercato, 323-55. [CrossRef]

Albert, Stuart, Blake E. Ashforth, and Jane E. Dutton. 2000. Introduction to special topic forum-Organizational identity and identification: Charting new waters and building new bridges. Academy of Management Review 25: 13-17. [CrossRef]

Armano, Emiliana, and Annalisa Murgia. 2017. Hybrid areas of work in Italy. Hypotheses to interpret the transformations of precariousness and subjectivity. In Mapping Precariousness, Labour Insecurity and Uncertain Livelihoods. Subjectivities and Resistance. Edited by Emiliana Armano, Arianna Bove and Annalisa Murgia. London and New York: Routledge, pp. 47-59.

Armstrong-Stassen, Marjorie. 2005. Coping with downsizing: A comparison of executive-level and middle managers. International Journal of Stress Management 12: 117-41. [CrossRef]

Avola, Maurizio. 2009. La differenziazione territoriale dei modelli di instabilità occupazionale in Italia. [The territorial differentiation of occupational instability in Italy]. In Vite Flessibili. Lavori, Famiglie e Stili di Vita di Giovani Coppie Meridionali. Edited by Palidda Rita. Milano: FrancoAngeli, pp. 15-50.

Avola, Maurizio, Laura Azzolina, and Marco Cuttone. 2017. Le politiche del lavoro e i servizi per l'impiego: Eredità passate e opportunità di innovazione [Labor policies and employment services: Past inheritances and opportunities for innovation]. Politiche Sociali 2: 317-34. [CrossRef]

Babbie, Earl. 2014. The Basics of Social Research. Belmont: Wadsworth Cengage, Belmont: OCLC.

Bagnara, Sebastiano, and Leonardo Bargigli. 2009. Job insecurity and successful re-employment: Examples from Italy. In Coping with Occupational Transitions: An Empirical Study with Employees Facing Job Loss in Five European Countries. Edited by Thomas Kieselbach, Sebastiano Bagnara, Hans De Witte, Louis Lemkow and Wilmar Schaufeli. Wiesbaden: Vs Verlag für Sozialwissenschaftenpp, pp. 225-78.

Bakker, Arnold B., and Evangelia Demerouti. 2017. Job demands-resources theory: Taking stock and looking forward. Journal of Occupational Health Psychology 22: 273-85. [CrossRef] [PubMed]

Baranowska, Anna, and Michael Gebel. 2010. The determinants of youth temporary employment in the enlarged Europe: Do labour market institutions matter? European Societies 12: 367-90. [CrossRef]

Berg, Bruce Lawrence, and Howard Lune. 2012. Qualitative Research Methods for the Social Sciences, 8th ed. Boston: OCLC.

Bertolini, Sonia, ed. 2018. Giovani Senza Futuro? Insicurezza Lavorativa e Autonomia Giovanile nell'Italia di Oggi [Young People without a Future? Job Insecurity and Youth's Autonomy in Today's Italy]. Roma: Carocci.

Bertolini, Sonia, Kiki Deliyanni-Kouimtzi, Magda Bolzoni, Chiara Ghislieri, Valentina Goglio, Simone Martino, Antonella Meo, Valentina Moiso, Rosy Musumeci, Roberta Ricucci, and et al., eds. 2018. Labour Market Insecurity and Social Exclusion: Qualitative Comparative Results in Nine Countries. EXCEPT Working Papers, WP No. 53. Tallinn, Estonia: Tallinn University. Available online: http://www.except-project.eu/ working-papers/(accessed on 13 January 2020).

Berton, Fabio, Matteo Richiardi, and Stefano Sacchi. 2009. Flexinsecurity: Perché in Italia la Flessibilità Diventa Precarietà [Flexinsecurity: Why in Italy the Flexibility Becomes Precarity]. Bologna: Il Mulino.

Blossfeld, Hans-P., Erik Klijzing, Melinda Mills, and Karin Kurz, eds. 2005. Globalization, Uncertainty and Youth in Society. London: Routledge.

Blustein, David L., Saliha Kozan, and Alice Connors-Kellgren. 2013. Unemployment and underemployment: A narrative analysis about loss. Journal of Vocational Behavior 82: 256-65. [CrossRef]

Carver, Charles S., Michael F. Scheier, and Kumari J. Weintraub. 1989. Assessing coping strategies: A theoretically based approach. Journal of Personality and Social Psychology 56: 267-83. [CrossRef]

Chiesa, Rita, Luca Fazi, Dina Guglielmi, and Marco G. Mariani. 2018. Enhancing Substainability: Psychological Capital, Perceived Employability, and Job Insecurity in Different Work Contract Conditions. Sustainability 10: 2475. [CrossRef]

Ciairano, Silvia, Emanuela Rabaglietti, Antonella Roggero, and Tiziana C. Callari. 2010. Life Satisfaction, Sense of Coherence and Job Precariousness in Italian Young Adults. Journal of Adult Development 17: 177-89. [CrossRef] 
Crompton, Rosemary. 1999. Restructuring Gender Relations and Employment: The Decline of the Male Breadwinner. Oxford and New York: Oxford University Press.

De Witte, Hans. 1999. Job insecurity and psychological well-being: Review of the literature and exploration of some unresolved issues. European Journal of Work and Organizational Psychology 8: 155-77. [CrossRef]

De Witte, Hans. 2005. Job Insecurity: Review of the International Literature on Definitions, Prevalence, Antecedents and Consequences. South African Journal of Industrial Psychology 31: 1-6. [CrossRef]

De Witte, Hans, and Nele De Cuyper. 2015. Job Insecurity and Employability. In Wiley Encyclopedia of Management. Hoboken: John Wiley \& Sons, Ltd. [CrossRef]

De Witte, Hans, Jaco Pienaar, and Nele De Cuyper. 2016. Review of 30 Years of Longitudinal Studies on the Association Between Job Insecurity and Health and Well-Being: Is There Causal Evidence? Australian Psychologist 51: 18-31. [CrossRef]

Denzin, Norman K., and Yvonna S. Lincoln. 2005. The Sage Handbook of Qualitative Research. Thousand Oaks: SAGE Publications.

Diener, Ed, Eunkook M. Suh, Richard E. Lucas, and Heidi L. Smith. 1999. Subjective well-being: Three decades of progress. Psychological Bullettin 125: 276-302. [CrossRef]

Diener, Ed, Richard E. Lucas, and Christie N. Scollon. 2006. Beyond the hedonic treadmill: Revising the adaptation theory of well-being. American Psychologist 61: 305-14. [CrossRef]

Esping-Andersen, Gøsta. 1999. The Social Foundations of Postindustrial Economies. Oxford: Oxford University Press.

Eurostat. 2017. Labour Force Survey. Available online: http://ec.europa.eu/eurostat/data/database (accessed on 18 October 2017).

Fana, Marta. 2019. Basta Salari da Fame! [No More Starvation Wages]. Bari: LaTerza.

Ferrera, Maurizio. 2012. Le Politiche Sociali. L'Italia in Prospettiva Comparata [Social policies. Italy in comparative perspective]. Bologna: Il Mulino.

Folkman, Susan, Schaefer Catherine, and Richard S. Lazarus. 1979. Cognitive processes as mediators of stress and coping. In Human Stress and Cognition: An Information-Processing Approach. Edited by Vernon Hamilton and David M. Warburton. London: Wiley, pp. 265-98.

Froud, Julie. 2019. The Enabling State? Well-Being, Foundational Economy and Citizenship. Paper presented at the State of Work (Lo Stato del Lavoro), IV Jobless Society Forum, Fondazione Giangiacomo Feltrinelli, Milan, Italy, June 12.

Fullin, Giovanna. 2004. Vivere L'instabilità del Lavoro [Living Job Instability]. Bologna: Il Mulino.

Ghislieri, Chiara, Claudio G. Cortese, Monica Molino, and Paola Gatti. 2019. The relationships of meaningful work and narcissistic leadership with nurses' job satisfaction. Journal of Nursing Management 27: 1691-99. [CrossRef]

Giunchi, Marianna, Federica Emanuel, Maria J. Chambel, and Chiara Ghislieri. 2016. Job insecurity, workload and job exhaustion in Temporary Agency Workers (TAWs): Gender differences. Career Development International 21: 3-18. [CrossRef]

Giunchi, Marianna, Anne-Marie Vonthron, and Chiara Ghislieri. 2019. Perceived Job Insecurity and Sustainable Wellbeing: Do Coping Strategies Help? Sustainability 11: 784. [CrossRef]

Goodman, Leo A. 1961. Snowball sampling. Annals of Mathematical Statistics 32: 148-70. [CrossRef]

Greenhalgh, Leonard, and Zehava Rosenblatt. 1984. Job insecurity: Toward conceptual clarity. The Academy of Management Review 9: 438-48. [CrossRef]

Hartley, Jean, Dan Jacobson, Bert Klandermans, and Tinka van Vuuren. 1991. Job Insecurity. London: Sage Publications.

Heuven, Ellen, Wilmar Schaufeli, and Arnold B. Bakker. 2009. Job insecurity and successful re-employment: Examples from The Netherlands. In Coping with Occupational Transitions: An Empirical Study with Employees Facing Job Loss in Five European Countries. Edited by Thomas Kieselbach, Sebastiano Bagnara, Hans De Witte, Louis Lemkow and Wilmar Schaufeli. Berlin: Springer, pp. 169-223.

International Labour Organization. 2016. Non-Standard Employment around the World: Understanding Challenges, Shaping Prospects. Geneva: International Labour Organization (ILO).

Istat. 2016. Religious Observances: Aspects of Daily Life: Regions and Type of Municipality. Rome: Istat.

Jahoda, Marie. 1982. Work, employment, and unemployment: Values, theories, and approaches in social research. The American Psychologist 36: 184-91. [CrossRef]

Krauss, Steven. 2005. Research Paradigms and Meaning Making: A Primer. The Qualitative Report 10: 758-70. 
László, Krisztina D., Hynek Pikhart, Mária S. Kopp, Martin Bobak, Andrzej Pajak, Sofia Malyutina, and Michael Marmot. 2010. Job insecurity and health: A study of 16 European countries. Social Science $\mathcal{E}$ Medicine (1982) 70: 867-74. [CrossRef]

Lazarus, Richard S., and Susan Folkman. 1984. Stress, Appraisal, and Coping. New York: Springer.

Merton, Robert K. 1949. Social Theory and Social Structure. New York: Free Press.

Molino, Monica, Valentina Dolce, Claudio G. Cortese, and Chiara Ghislieri. 2018. Personality and social support as determinants of entrepreneurial intention. Gender differences in Italy. PLoS ONE 13: e0199924. [CrossRef] [PubMed]

Molino, Monica, Claudio G. Cortese, and Chiara Ghislieri. 2019. Unsustainable Working Conditions: The Association of Destructive Leadership, Use of Technology, and Workload with Workaholism and Exhaustion. Sustainability 11: 446. [CrossRef]

Näswall, Katharina, and Hans De Witte. 2003. Who feels insecure in Europe? Predicting job insecurity from background variables. Economic and Industrial Democracy 24: 189-215. [CrossRef]

Naticchioni, Paolo, and Silvia Muzi. 2007. Labour Market Flexibility and Family Choices: A Comparative Perspective in the EU. In Job Instability and Family Trends. Roma: Quaderni della Fondazione G. Brodolini, pp. 269-93.

Ojala, Brigitta, Clas-Hakan Nygård, Heidi Huhtala, Philip Bohle, and Seppo T. Nikkari. 2019. A Cognitive Behavioural Intervention Programme to Improve Psychological Well-Being. International Journal of Environmental Research and Public Health 16: 80. [CrossRef]

Paul, Karsten, and Klaus Moser. 2009. Unemployment impairs mental health: Meta-analyses. Journal of Vocational Behavior 74: 264-82. [CrossRef]

Piccoli, Beatrice, Antonino Callea, Flavio Urbini, Antonio Chirumbolo, Emanuela Ingusci, and Hans De Witte. 2017. Job insecurity and performance: The mediating role of organizational identification. Personnel Review 46: 1508-22. [CrossRef]

Pinquart, Martin, and Rainer K. Silbereisen. 2008. Coping with Increased Uncertainty in the Field of Work and Family Life. International Journal of Stress Management 15: 209-21. [CrossRef]

Reyneri, Emilio. 2017. Introduzione alla Sociologia del Mercato del Lavoro [Introduction to the Sociology of Labour Market]. Bologna: Il Mulino.

Reyneri, Emilio, and Federica Pintaldi. 2013. Dieci Domande su un Mercato del Lavoro in Crisi [Ten Questions on a Labour Market in Crisis]. Bologna: Il Mulino.

Richter, Anne. 2011. Job Insecurity and Its Consequences. Investigating Moderators, Mediators and Gender. Ph.D. Thesis, Department of Psychology, Stockholm University, Stockholm, Sweden. Available online: https://www.diva-portal.org/smash/get/diva2:453238/FULLTEXT01.pdf (accessed on 13 January 2020).

Rosina, Alessandro. 2018. Il Futuro Non Invecchia [The Future Does Not Get Old]. Milano: Vita e Pensiero.

Saraceno, Chiara, and Wolfgang Keck. 2010. Can we identify intergenerational policy regimes in Europe? European Societies 12: 675-96. [CrossRef]

Savickas, Mark L., Laura Nota, Jerome Rossier, Jean-Pierre Dauwalder, Maria Eduarda Duarte, Jean Guichard, Salvatore Soresi, Raoul Van Esbroeck, and Annelies E.M. van Vianen. 2009. Life designing: A paradigm for career construction in the 21st century. Journal of Vocational Behavior 75: 239-50. [CrossRef]

Sgritta, Giovanni B. 2014. De-generazione: Il patto violato. Sociologia del lavoro 136: 279-94. [CrossRef]

Spanò, Antonella. 2017. I Giovani del Sud di Fronte alla Crisi [The Southern Youth Facing the Crisis]. Milano: FrancoAngeli.

Steger, Michael, and Bryan Dik. 2009. Work as Meaning: Individual and Organizational Benefits of Engaging in Meaningful Work. In Oxford Handbook of Positive Psychology and Work. Oxford: Oxford University Press. Available online: http://www.oxfordhandbooks.com/view/10.1093/oxfordhb/9780195335446.001.0001/ oxfordhb-9780195335446-e-11 (accessed on 16 December 2017).

Sverke, Magnus, and Johnny Hellgren. 2002. The Nature of Job Insecurity: Understanding Employment Uncertainty on the Brink of a New Millennium. Applied Psychology. [CrossRef]

Tajfel, Henri, and John C. Turner. 1979. An integrative theory of intergroup conflict. In The Social Psychology of Intergroup Relations. Edited by William G. Austin and Stephen Worchel. Monterey: Brooks-Cole, pp. $33-47$.

Van Hoye, Greet, and Hanne Lootens. 2013. Coping with unemployment: Personality, role demands, and time structure. Journal of Vocational Behavior 82: 85-95. [CrossRef] 
Van Knippenberg, Daan, Barbara Van Knippenberg, Laura Monden, and Fleur de Lima. 2002. Organizational identification after a merger: A social identity perspective. British Journal of Social Psychology 87: 233-52. [CrossRef]

Van Vuuren, Tinka. 1990. Met Ontslag Bedreigd. Werknemers in Onzekerheid over Hun Arbeidsplaats bij Veranderingen in de Organisatie. Amsterdam: VU-uitgeverij.

Wang, Hai-jiang, Chang-qin Lu, and Oi-ling Siu. 2015. Job insecurity and job performance: The moderating role of organizational justice and the mediating role of work engagement. Journal of Applied Psychology 100: 1249-58. [CrossRef]

Warr, Peter B. 1990. Decision latitude, Job demands and employee well being. Work Stress 4: 285-94. [CrossRef] Xanthopoulou, Despoina, Arnold B. Bakker, Envagelia Demerouti, and Wilwar B. Schaufeli. 2007. The role of personal resources in the job demands-resources model. International Journal of Stress Management 14: 121-41. [CrossRef]

(c) (

(C) 2020 by the authors. Licensee MDPI, Basel, Switzerland. This article is an open access article distributed under the terms and conditions of the Creative Commons Attribution (CC BY) license (http://creativecommons.org/licenses/by/4.0/). 